\title{
Anti-peptide autoantibodies and fatal anaphylaxis in NOD mice in response to insulin self-peptides B:9-23 and B:13-23
}

\author{
Edwin Liu, ${ }^{1,2}$ Hiroaki Moriyama, ${ }^{1}$ Norio Abiru, ${ }^{1}$ Dongmei Miao, ${ }^{1}$ Liping Yu, ${ }^{1}$ \\ Robert M. Taylor, ${ }^{1}$ Fred D. Finkelman, ${ }^{3}$ and George S. Eisenbarth ${ }^{1}$ \\ ${ }^{1}$ Barbara Davis Center for Childhood Diabetes, University of Colorado Health Sciences Center, Denver, Colorado, USA \\ ${ }^{2}$ Section of Gastroenterology, Hepatology and Nutrition, The Children's Hospital, University of Colorado \\ Health Sciences Center, Denver, Colorado, USA \\ ${ }^{3}$ Division of Immunology, University of Cincinnati College of Medicine, Cincinnati Veterans Administration Medical Center, \\ and Children's Hospital Medical Center, Cincinnati, Ohio, USA
}

\begin{abstract}
There is evidence that amino acids 9-23 of the insulin B chain are a major target of anti-islet autoimmunity in type 1 diabetes. Administration of this peptide to NOD mice prevents diabetes, and phase I trials of an altered peptide ligand of B:9-23 are underway in humans. We were interested in longterm subcutaneous therapeutic administration of B:9-23 without adjuvant. To our initial surprise, the peptide consistently induced fatal anaphylaxis in NOD mice after 6 weeks of administration. Anaphylaxis could be blocked by a combination of antihistamine and platelet-activating factor antagonist (but neither alone) or by a combination of anti-IgG receptor and anti-IgE antibodies. High titers of anti-B:9-23 antibodies were induced within 3-4 weeks of immunization with the peptide. Peptide B:13-23 also induced anaphylaxis and was more potent than peptide B:9-23. Antibodies induced by peptide B:9-23 and peptide B:13-23 did not cross-react with each other. Thus, the insulin peptides B:9-23 and B:13-23, even when administered subcutaneously in the absence of adjuvant, can induce a dramatic humoral response leading to fatal anaphylaxis in NOD mice.
\end{abstract}

J. Clin. Invest. 110:1021-1027 (2002). doi:10.1172/JCI200215488.

\section{Introduction}

Type $1 \mathrm{~A}$ diabetes (the immune-mediated form of diabetes mellitus) occurs in many species. The NOD mouse is a particularly well-studied animal model. T cells of NOD mice target multiple islet molecules, and a recent international workshop found consistent evidence for specific anti-insulin autoantibodies (1). There is evidence in both humans and NOD mice for intraand intermolecular epitope spreading with progression to diabetes (2-5), and $\mathrm{T}$ cell clones reacting with multiple antigens in mice rapidly transfer diabetes (6).

Our group has been particularly interested in autoimmunity directed at insulin following the discovery by Daniel, Wegmann, and colleagues that the majority of islet $\mathrm{CD}^{+}$infiltrating $\mathrm{T}$ cells recognize insulin and that, of such $\mathrm{T}$ cells, more than $90 \%$ react with the amino acids 9-23 of the insulin B chain (B:9-23) $(6,7)$. The NOD CD4 ${ }^{+} \mathrm{T}$ cell clones recognizing B:9-23 usually express the $V \alpha 13.3$ chain variable segment with J $\alpha 45$ or J $\alpha 34$ but have no apparent restriction of the nDn junction (8). Two different epitopes, B:9-16 and B:13-23, which share only four

Received for publication March 20, 2002, and accepted in revised form August 6, 2002.

Address correspondence to: George S. Eisenbarth, 4200 East Ninth Avenue, Box B140, Denver, Colorado 80262, USA. Phone: (303) 315-4891; Fax: (303) 315-4892;

E-mail: George.Eisenbarth@uchsc.edu.

Conflict of interest: No conflict of interest has been declared. Nonstandard abbreviations used: subcutaneous (SQ); plateletactivating factor (PAF). amino acids, B:13-16 (EALY), within B:9-23, are recognized by the AV13S3 T cell clones (9).

In the NOD mouse, $\mathrm{CD}^{+}$anti-B:9-23 $\mathrm{T}$ cells were present in islets at the earliest time studied (4 weeks of age); a NOD CD8 pathogenic T cell clone reacting with peptide B:15-23 has also been described (10). Even in $\mathrm{BALB} / \mathrm{c}$ mice, administration of the B:9-23 peptide induces high levels of antibodies that react with intact insulin and are not absorbed by the peptide (11). This B:9-23 insulin sequence is identical in multiple species, including humans and mice. Human T cells reacting with B:9-23 were detected in new-onset and at-risk patients using an ELISPOT assay (12). Recently the crystal structure of the B:9-23 peptide bound to DQ8 was described (13). An altered-peptide ligand of the insulin peptide B:9-23 is able to suppress diabetes in NOD mice and is in phase I clinical trials in humans (12).

Self-peptides have been considered poor immunogens, but a recent phase II clinical trial in patients with multiple sclerosis using an altered-peptide ligand of a myelin basic protein peptide resulted in immediate hypersensitivity reactions in a subset of patients (14). Similarly, mice immunized with the self-antigen myelin proteolipid protein experienced anaphylactic shock (15). Following prevention studies of the B:9-23 peptide in adjuvant, we began studies of the subcutaneous (SQ) administration in saline of B:9-23 peptide. Such administration was chosen to avoid the difficulty of using adjuvants, and multiple injections were chosen to enhance disease prevention. In the first experiment, with a $100-\mu \mathrm{g}$ dose of peptide B:9-23, eight of ten mice 
Summary of peptide-induced anaphylaxis in the NOD mice

\begin{tabular}{lcccccccc}
\hline & B:9-23 & B:9-23 & TT:830-843 & B:9-23 & B:13-23 & B:9-23 & TT:830-843 & B:13-23 \\
& $100 \mu \mathrm{g} /$ dose & $100 \mu \mathrm{g} /$ dose & $10 \mu \mathrm{g} /$ dose & $10 \mu \mathrm{g} / \mathrm{dose}$ & $10 \mu \mathrm{g} /$ dose & $10 \mu \mathrm{g} /$ dose & $10 \mu \mathrm{g} / \mathrm{dose}$ & $10 \mu \mathrm{g} / \mathrm{dose}$ \\
& 4 or 6 weeks & 11 weeks & 4 weeks & 4 weeks & 4 weeks & 11 weeks & 11 weeks & $10-11$ weeks \\
Number of mice & 36 & 6 & 10 & 25 & 6 & 10 & 10 \\
Number anaphylaxis & 36 & $6^{\mathrm{A}}$ & 0 & 0 & 6 & 0 & 15 \\
Percent anaphylaxis & 100 & $100^{\mathrm{A}}$ & 0 & 0 & 100 & 0 & 0 & 13 \\
\end{tabular}

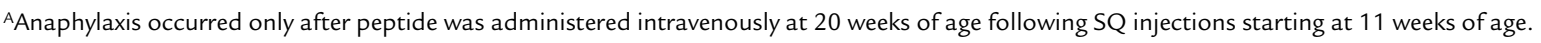

died of apparent acute anaphylaxis minutes after injection during the seventh week of treatment. This led to the current study of insulin peptide induction of autoantibodies and anaphylaxis.

\section{Methods}

Mice and induction of anaphylaxis. Female NOD mice were obtained from Taconic (Germantown, New York, USA) and housed in the pathogen-free animal colony at the Barbara Davis Center for Childhood Diabetes. The mice were injected with HPLC-purified insulin peptide B:9-23 (Research Genetics, Huntsville, Alabama, USA). Briefly, the peptide was dissolved in sterile saline and adjusted to a neutral $\mathrm{pH}$, at a concentration of $100 \mu \mathrm{g}$ in $100 \mu \mathrm{l}$. A total of $100 \mu \mathrm{g}$ of B:9-23 was injected subcutaneously in the scruff of the neck, starting at 4-6 weeks of age or at 11 weeks of age, and given on days 1-5 and 8 and then weekly thereafter. Alternatively, B:9-23, B:13-23, or tetanus toxin peptide (TT:830-843) was administered at a dose of $10 \mu \mathrm{g}$ in $100 \mu \mathrm{l}$ of saline, starting at 4 weeks of age or 10-11 weeks of age. Mice were monitored for clinical signs of anaphylaxis (see below). Consistently, onset of anaphylaxis occurred 6 weeks from the start of B:9-23 peptide immunization (100 $\mu \mathrm{g} /$ dose) in the mice immunized subcutaneously at 4-6 weeks of age but was not observed when subcutaneous immunization started at 11 weeks of age. Five weeks from the start of $\mathrm{B}: 13-23$ peptide immunizations (10 $\mu \mathrm{g} / \mathrm{dose}$ ), anaphylaxis occurred in the mice, regardless of age at immunization. There were no clinical signs of anaphylaxis in the mice immunized with B:9-23 or TT:830-843 at $10 \mu \mathrm{g} /$ dose regardless of age at immunization. Serum for antibody measurement was obtained on a weekly basis, also starting at 4 weeks of age, and blood glucose was monitored weekly using the Glucometer Elite blood glucose meter (Bayer Corp., Mishawaka, Indiana, USA) starting at 12 weeks of age. Any diabetic mouse (defined as blood glucose > 250 $\mathrm{mg} / \mathrm{dl}$ on two consecutive measurements) was sacrificed (there were only two in the B:13-23 group immunized at 11 weeks of age).

Monitoring of anaphylaxis. A clinical scoring system was developed to monitor anaphylaxis in the mice based on activity and level of alertness: A 0 score represented normal behavior, 1 represented decreased spontaneous activity, 2 represented decreased activity with falling over and a loss of the self-righting reflex, and 3 was assigned to mice that became moribund with cool, cyanotic extremities. Excessive scratching was observed early in most mice that had clinical anaphylaxis but was not included in the scoring system. A score of $0-3$ was given to each mouse before injection with insulin peptide and every 5 minutes following induction of anaphylaxis for the next 30 minutes. In addition, temperature was recorded by the use of a rectal probe and thermometer (451 Probe and 4600 Precision Thermometer; Yellow Springs Instrument Co., Yellow Springs, Ohio, USA) to monitor changes in core temperature. Decreased core temperature is associated with most forms of shock, including anaphylactic shock. Any mouse that became moribund or experienced prolonged anaphylaxis beyond 30 minutes was sacrificed. Mice that recovered from anaphylaxis were restudied 1 or more weeks later.

Protection from anaphylaxis. To determine the mechanism of anaphylaxis, mice were pretreated with triprolidine (Sigma-Aldrich, St. Louis, Missouri, USA), an H1 antihistamine, CV-6209 (Wako Chemicals USA Inc., Richmond, Virginia, USA), a platelet-activating factor (PAF) antagonist, or a combination of both. Triprolidine was prepared at a final concentration of $200 \mu \mathrm{g}$ in $100 \mu \mathrm{l}$ of sterile PBS and injected intraperitoneally 45 minutes before induction of anaphylaxis. CV-6209 was prepared at a concentration of $66 \mu \mathrm{g}$ in $100 \mu \mathrm{l}$ of sterile saline, adjusted to neutral $\mathrm{pH}$, and injected intravenously 5 minutes prior to induction of anaphylaxis. Control mice received sterile saline intraperitoneally or intravenously. $\mathrm{H} 1$ antagonists have been shown to inhibit murine anaphylaxis that is mediated by $\operatorname{IgE}$ antibodies and mast cells, while PAF antagonists have been shown to inhibit murine anaphylaxis that is mediated by IgG antibodies and macrophages (16). A second group of mice was pretreated with $0.5 \mathrm{mg}$ of $2.4 \mathrm{G} 2$, a rat IgG2b mAb that reacts with two mouse receptors for the Fc fragment of IgG (FcyRII and FcyRIII) (American Type Culture Collection, Rockville, Maryland, USA), or $0.2 \mathrm{mg}$ of EM95, a rat IgG2a mAb that reacts with mouse IgE antibodies (Zelig Eshhar, Weizmann Institute of Science, Rehovot, Israel), or with both mAb's. J1.2, a rat IgG2b mAb, and GL117, a rat IgG2a mAb (both from John Abrams, DNAX Research Institute, Palo Alto, California, USA), were administered as control antibodies. Antibodies were produced as ascites in pristane-primed nude mice and purified by ammo- 


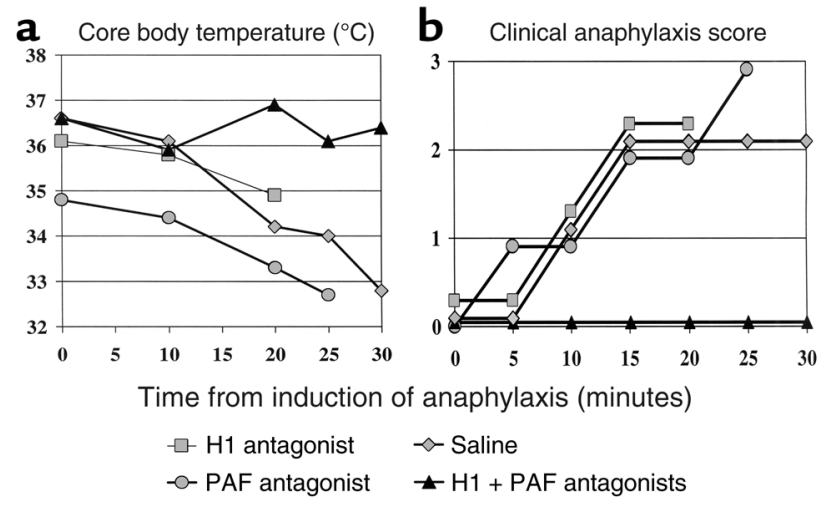

Figure 1

(a) Core body temperature and (b) clinical anaphylaxis score of NOD mice sensitized and induced with B:9-23 peptide. Examples of mice pretreated with $\mathrm{H} 1$ antagonist, PAF antagonist, saline, or both $\mathrm{H} 1$ and PAF antagonist are shown. Single therapy with the $\mathrm{H} 1$ antagonist, PAF antagonist, or nothing resulted in rapid, and often fatal, anaphylaxis.

nium sulfate fractionation and DE-52 ion exchange chromatography. All antibodies were injected subcutaneously in the scruff of the neck 24 hours prior to the induction of anaphylaxis. EM95 has been shown to inhibit murine anaphylaxis that is mediated by $\operatorname{IgE}$ antibodies and mast cells, while 2.4G2 has been shown to inhibit murine anaphylaxis that is mediated by $\operatorname{IgG}$ antibodies and macrophages (16).

Measurement of anti-B:9-23 antibodies. As stated earlier, mice were bled, and serum was obtained weekly and stored at $-4^{\circ} \mathrm{C}$ until assayed. Antibodies against insulin peptide B:9-23 were measured by ELISA. High-binding Costar EIA/RIA 96-well plates (Corning Inc., Life Sciences, Acton, Massachusetts, USA) were coated overnight at room temperature with $1 \mu \mathrm{g}$ of B:9-23 in $100 \mu \mathrm{l}$ of PBS per well. After this, wells were blocked with a buffer containing PBS, $2 \%$ BSA, and $0.01 \%$ sodium azide for a minimum of 2 hours at room temperature. Next, serum samples were diluted at either 1:500 or 1:30,000 in blocking buffer and incubated in each well for 2 hours. Biotin-conjugated rat anti-mouse IgG1 mAb (BD Biosciences, PharMingen, San Diego, California, USA) was diluted 1:5,000 in PBS, and $100 \mu \mathrm{l}$ was added to each well for 30 minutes. Afterwards, 100 $\mu \mathrm{l}$ of streptavidin-horseradish peroxidase conjugate (BD PharMingen, USA), diluted 1:4,000 in PBS, was placed in each well for 15 minutes. Lastly, 3,3',5, $5^{\prime}$ tetramethylbenzidine substrate (BD PharMingen, USA) was added, and absorbance at 450 and $550 \mathrm{~nm}$ was analyzed with a Bio-Rad model 3550 Microplate Reader (Bio-Rad Laboratories Inc., Life Science Research Group, Hercules, California, USA).

Absorption experiments were performed using the ELISA technique described above. However, before the 1:30,000-diluted serum samples were placed into the 96-well plate, the samples were preincubated with B:9-23, B:13-23, whole insulin, or TT:830-843 at concentrations of $10 \mu \mathrm{g} / \mathrm{ml}$ down to $0.01 \mu \mathrm{g} / \mathrm{ml}$ by tenfold serial dilutions. After 20 minutes, the samples were loaded onto the 96-well plate and the remainder of the protocol was completed.

To measure the dose-dependent response of anti-B:923 antibodies in mice, 4-week-old female BALB/c mice were immunized with B:9-23 $(10 \mu \mathrm{g} /$ dose or 100 $\mu \mathrm{g} /$ dose) using the same schedule. ELISA assay was performed as described above using serum diluted at 1:500. However, rather than streptavidin-horseradish peroxidase for detection, streptavidin-europium $(0.1$ $\mathrm{mg} / \mathrm{ml}$ ) was used at a concentration of $5 \mu \mathrm{l}$ in $10 \mathrm{ml}$ of PBS, at $100 \mu \mathrm{l}$ per well for 15 minutes. Afterward, the plate was washed, $200 \mu \mathrm{l}$ of enhancement solution (Delphia; Wallac Oy, Turku, Finland) was added to the wells, and the wells were gently shaken for 10 minutes before being placed on the fluorometer.

The results are given in cpm; an index was calculated based on positive and negative standards. The formula for the B:9-23 index is (sample cpm - negative control $\mathrm{cpm}) /($ positive control cpm - negative control cpm). For NOD and $\mathrm{BALB} / \mathrm{c}$ mice immunized with high-dose B:9-23 $(100 \mu \mathrm{g} /$ dose $)$, the lower limit of detection was $1: 10^{6}$. For mice immunized with low-dose B:9-23 (10 $\mu \mathrm{g} /$ dose), the lower limit of detection for anti-B:9-23 IgG1 antibodies, was less than 1:30,000.

\section{Results}

Anaphylaxis, as defined above, was consistently induced after 6 weeks of repeated SQ injections of B:9-23 $(100 \mu \mathrm{g} / \mathrm{dose})$ to NOD mice when the injections started at an early age (4-6 weeks) but not when they started at 11 weeks. Interestingly, the older (11week-old) mice were resistant to anaphylaxis even after 10 weeks of SQ injections of B:9-23 (100 $\mu \mathrm{g} /$ dose). However, anaphylaxis could be induced in these mice (six of six) when peptide was given intravenously at 20 weeks of age following SQ immunizations begun at 11 weeks. This was an extremely vigorous anaphylactic response with five fatalities within 10 minutes. Neither peptide B:9-23 nor a control tetanus toxin peptide (TT:830-843) induced anaphylaxis when administered SQ at $10 \mu \mathrm{g} /$ dose. For mice receiving the peptide B:13$23(10 \mu \mathrm{g} / \mathrm{dose})$, onset of anaphylaxis was predictably

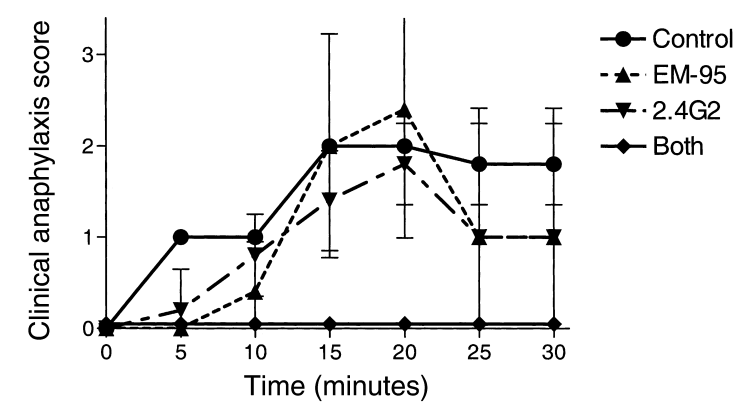

Figure 2

Clinical anaphylaxis score of NOD mice sensitized and induced to experience anaphylaxis with B:9-23 peptide. Mice were pretreated with control antibodies, EM95, 2.4G2, or both EM95 and 2.4G2. 


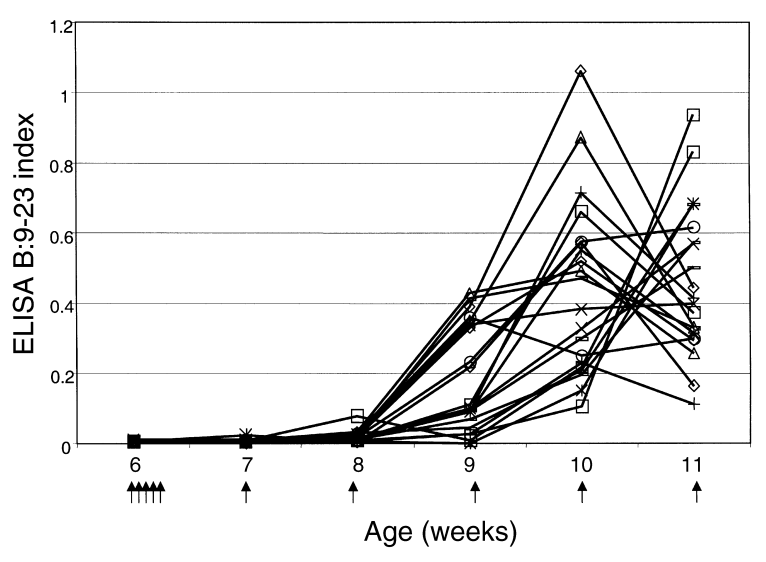

Figure 3

IgG1 antibodies to B:9-23 are detectable within 3 weeks of weekly B:9-23 immunization ( $100 \mu \mathrm{g} /$ dose) and peak $2-3$ weeks prior to anaphylaxis, in NOD mice. Anaphylaxis occurred at 12 weeks of age in this experiment. Serum obtained from mice is diluted 1:30,000 prior to measurement (lower limit of detection is $1: 10^{6}$ dilution). Various symbols represent the anti-B:9-23 antibody level in individual mice followed over multiple injections. Arrows represent a subcutaneous injection of B:9-23 peptide.

6 weeks after the institution of repeated injections, whether the injections started at 4 or at 11 weeks.

The induction of anaphylaxis is summarized in Table 1. All mice eventually experienced anaphylaxis when immunized with B:9-23 (100 $\mu \mathrm{g} / \mathrm{dose})$ starting at 4 weeks of age, and 19 of 21 mice experienced anaphylaxis when immunized with B:13-23, irrespective of age at start of immunization. (Two developed diabetes and were sacrificed prior to development of anaphylaxis.) Treatment with B:9-23 or TT:830-843 at $10 \mu \mathrm{g} /$ dose, when started at any age, did not induce anaphylaxis.

We determined the H1- and PAF-dependence of peptide immunization-induced anaphylaxis by treating mice with $\mathrm{H} 1$ and/or PAF antagonists prior to the last of a series of peptide injections. Anaphylaxis was induced in these mice with either B:9-23 $(100 \mu \mathrm{g} /$ dose $)$ starting at 4 weeks of age or B:13-23 $(10 \mu \mathrm{g} / \mathrm{dose})$ starting at 11 weeks of age. Both of two mice experienced anaphylaxis (one fatally) following injection of either peptide B:9-23 or B:13-23 despite pretreatment with the PAF antagonist. Both of two mice pretreated with the $\mathrm{H} 1$ antagonist also experienced anaphylaxis (one fatally). Nine of nine mice pretreated with both the PAF antagonist and the $\mathrm{H} 1$ antagonist (in a total of 14 trials of anaphylaxis induction) remained asymptomatic and free of anaphylaxis. These nine mice experienced anaphylaxis in later trials that used saline pretreatment. Six additional mice pretreated with saline placebo prior to induction (for a total of 15 of 15 mice) also experienced anaphylaxis following insulin peptide administration, and 7 of 15 died. Figure 1 demonstrates examples of rectal temperature and clinical anaphylaxis scoring results.

To evaluate the IgE and IgG dependence of anaphylaxis, 19 NOD mice were primed with B:9-23 peptide
$(100 \mu \mathrm{g} /$ dose starting at 6 weeks of age) and anaphylaxis was induced 6 weeks later. Five of five mice pretreated with anti-Fc $\gamma \mathrm{RII} / \mathrm{RIII} \mathrm{mAb}$ and four of five mice pretreated with anti-IgE $\mathrm{mAb}$ experienced anaphylaxis, and three anti-IgE mAb-treated mice died. All four mice pretreated with both anti-IgE and anti-Fc $\gamma \mathrm{RII} / \mathrm{RIII} \mathrm{mAb}$ 's remained asymptomatic, while all five mice that received both control mAb's experienced anaphylaxis and one died (Figure 2).

High titers of antibodies reacting with either B:9-23 peptide or B:13-23 peptide were detected. IgG1 antibodies to the B:9-23 peptide ( $100 \mu \mathrm{g} /$ dose) were detected within 3 weeks of immunization and peaked approximately 3 weeks prior to the onset of clinically detectable anaphylaxis (Figure 3 ). These antibodies were still detectable above assay background at a dilution of sera of $1: 10^{6}$. Figure 4 demonstrates the anti-B:9-23 levels in mice immunized with B:9-23 at $10 \mu \mathrm{g} /$ dose. The antibody levels were considerably lower and were detected at a dilution of 1:500. Unimmunized or control TT:830-843-immunized mice did not develop antibodies to B:9-23 that were detectable by ELISA (data not shown). The anti-B:9-23 peptide antibodies were not absorbed by intact insulin nor did they cross-react with B:13-23. However, they were absorbed by the immunizing peptide B:9-23 (Figure 5). Similarly, B:13-23-induced antibodies were absorbed by B:13-23 but not by B:9-23. Although mice immunized with B:9-23 at $10 \mu \mathrm{g} /$ dose had detectable anti-B:9-23 antibodies, they were at a lower titer. An example of this is shown in Figure 6, where BALB/c mice (which do not express spontaneous insulin autoantibodies but do recognize the B:9-23 peptide) are seen to have a dose-dependent anti-B:9-23 response. Similar to the older (11 weeks) NOD mice, these mice were resistant to B:9-23-induced anaphylaxis when injection was subcutaneous but did develop vigorous anaphylaxis when B:9-23 was given intravenously after subcutaneous priming. Thus far, we have not been able to detect, with a similar assay format, IgE antibodies to B:9-23 or B:13-23 in the NOD or $\mathrm{BALB} / \mathrm{c}$ mouse.

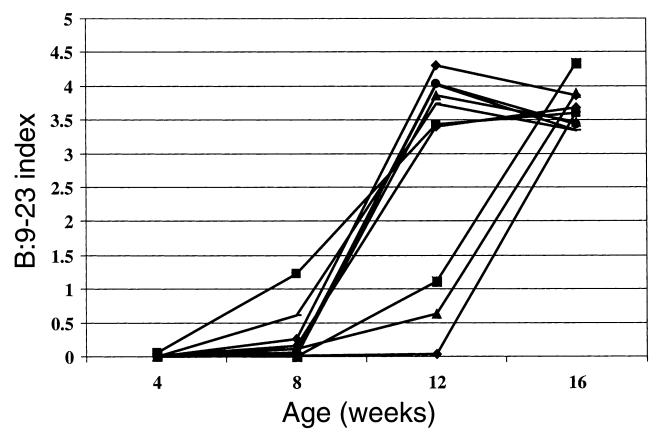

\section{Figure 4}

NOD mice immunized with a lower dose of B:9-23 (10 $\mu \mathrm{g} /$ dose $)$ also develop anti-B:9-23 antibodies, but in lower levels that are better detected at dilutions of 1:500. 


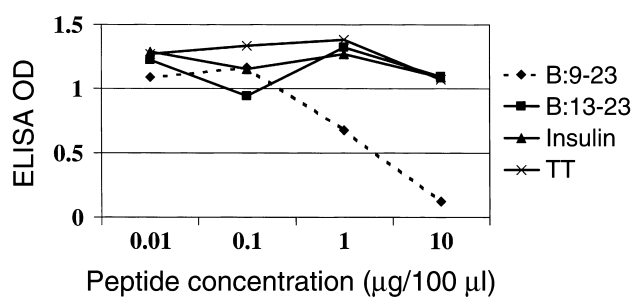

Figure 5

Anti-B:9-23 antibodies are absorbed by B:9-23 peptide and not by insulin, B:13-23, or tetanus toxin (TT). This competition experiment was done at 1:30,000 dilution in serum of NOD mice immunized with B:9-23 (100 $\mu \mathrm{g} /$ dose $)$.

\section{Discussion}

Both IgE and IgG1 can elicit allergic reactions in mice (17), whereas IgG antibodies have not been clearly demonstrated to have a role in human anaphylaxis. PAF is the main mediator of $\operatorname{IgG}$ antibody-induced active and passive anaphylactic shock in the mouse (18, 19), whereas histamine has a major role in IgE-mediated murine anaphylaxis (20). PAF is elaborated from a variety of cells, including neutrophils, basophils, mast cells, monocytes, macrophages, platelets, and endothelial cells. The predominant receptor for IgG1 antibodies leading to anaphylaxis is FcyRIII (21-23), with Fc $\gamma$ RII functioning as an inhibitory receptor (24). Although IgG1 is the main activator of PAF secretion, studies of mast cell-deficient mice indicate that $\operatorname{IgE}$ is also capable of inducing other cells to elaborate PAF (25). IgE-antigen interactions cause cross-linking of the FcERI and subsequent mast cell activation $(21,26)$. Mice deficient in this receptor are protected from passive cutaneous (26) and passive systemic anaphylaxis (27). However, evidence of $\operatorname{IgE}$ interactions with Fc $\gamma$ RII/III suggests a more complex IgE-mediated response than previously thought (23). In fact, previous studies have demonstrated that the major mediators of mouse anaphylactic shock vary with the strain. For example, BALB/c mice sensitized with BSA emulsified with CFA suffered lethal anaphylaxis that was blocked by either cyproheptadine (an antihistamine, antiserotonin agent) or CV-6209 separately. The C57BL/6 mouse, however, required both cyproheptadine and CV-6209 in combination to adequately prevent lethal shock. Kimura et al. concluded from this that mouse active anaphylactic shock could be classified into the following four types: (a) suppressible by cyproheptadine but not by CV-6209, (b) suppressible by CV-6209 but not by cyproheptadine, (c) suppressible by both, and (d) not suppressible by either (28).

In our self-peptide model of anaphylaxis, development of anaphylaxis is dependent on the peptide and dose (B:9-23, $100 \mu \mathrm{g}$; and B:13-23, $10 \mu \mathrm{g}$ ). With regard to $\mathrm{B}: 9-23$ induction, age at induction may also be a factor, with younger mice being more susceptible than older mice. However, when we modified our mode of antigen delivery in the older, "resistant" mice by giving peptide intravenously, we induced a vigorous anaphy- lactic response that was fatal in five of six mice within 10 minutes. Furthermore, anaphylaxis is also more difficult to induce in 4-week-old BALB/c mice despite the formation of $\operatorname{IgG} 1$ anti-peptide antibodies. The ability to eventually induce anaphylaxis with an intravenous dose of B:9-23 suggests a quantitative difference but not an absolute difference between the strains. We find that mice rapidly develop high-titer IgG1 antibodies to $\mathrm{B}: 9-23$ or $\mathrm{B}: 13-23$ and anaphylaxis in response to repeated self-peptide immunizations in the absence of adjuvant. The antibody response in mice to B:9-23 is dose-dependent. Tetanus toxin peptide, a peptide to which NOD mice respond with T cell proliferation, did not induce antibodies to B:9-23 nor did it induce anaphylaxis. Neither the PAF antagonist nor the $\mathrm{H} 1$ antagonist alone prevented anaphylaxis. However, when they are used in combination, all mice are protected. Furthermore, prevention of anaphylaxis is achieved with

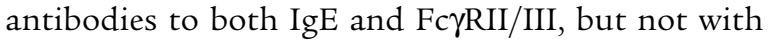
antibodies to only IgE or only Fc $\gamma \mathrm{RII} / \mathrm{III}$. This suggests that PAF and histamine are both involved in the hypersensitivity reaction induced by B:9-23 or B:13-23. Each mediator is capable, independently of the other, of promoting the self-peptide-induced fatal anaphylaxis. These findings are consistent with current knowledge that both IgE and IgG1 are involved in systemic anaphylaxis in mice, as well as observations that both PAF and histamine can mediate this process. Complete protection is possible only through the synergistic effects of a PAF antagonist and an $\mathrm{H} 1$ antagonist, or by blocking both $\operatorname{IgE}$ and $\operatorname{IgG}$. This supports the notion that histamine and PAF are predominantly responsible for the self-peptide-induced anaphylaxis, and that all other mediators can only play a minor role.

IgG1 antibodies to B:9-23 are consistently seen in high titers 3 weeks prior to the onset of clinical anaphylaxis. Antibodies to this self-peptide have not been previously reported in the NOD mouse, and although insulin autoantibodies were present in NOD mice without peptide immunization and increased following administration of the B:9-23 peptide, antibodies to

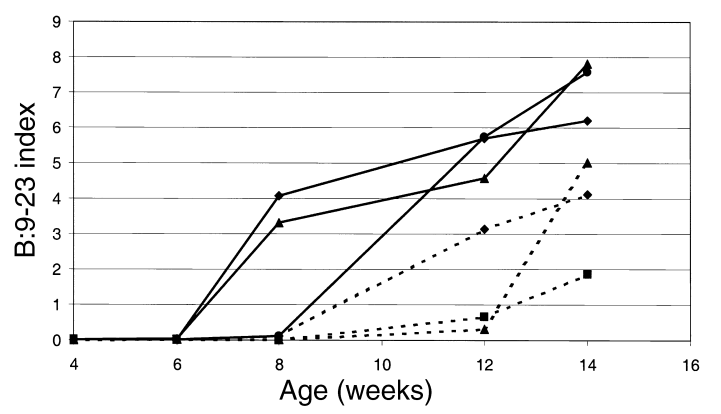

Figure 6

$\mathrm{BALB} / \mathrm{c}$ mice recognize $\mathrm{B}: 9-23$ peptide and develop an IgG1 antipeptide response that is dose-dependent. Solid lines represent anti-B:9-23 antibodies in mice receiving repeated injections of $\mathrm{B}: 9-23$ at $100 \mu \mathrm{g} / \mathrm{dose}$, whereas dashed lines represent mice receiving B:9-23 at $10 \mu \mathrm{g} /$ dose. Serum was diluted at 1:500 for assay. 
the peptide were not detectable in the absence of subcutaneous peptide administration (data not shown). It is not known why it is so easy to induce high titers of antibodies to certain self-peptides such as insulin B:9-23 and myelin basic protein, while most studies in the past indicate "tolerance" to self-peptides (17). A recent report documenting induction of antibodies to a myelin peptide suggested a potential link with absence of thymic expression of the peptide $(29,30)$. Transgenes using the rat insulin promoter are expressed within the thymus. A considerable body of evidence indicates that insulin is present in thymus of humans and mice (31-33), and low concentrations of insulin are certainly present following secretion by islet cells throughout the body. Thomas and coworkers, using transgenic anti-insulin antibody genes, have provided evidence for induction of tolerance to insulin (34). It is possible that though insulin/proinsulin is present within the thymus, the specific insulin peptides we are studying are not presented, though there is considerable evidence that these $B$ chain peptides are clearly recognized by $\mathrm{T}$ cells of the spontaneous NOD disease model. This ease of recognition may alternatively contribute to their strong immunogenicity, for both disease pathogenesis and induction of anaphylaxis. It actually may be easier to induce anaphylaxis with autoantigenic self-peptides in the absence of adjuvant than with foreign antigens.

Type 1 diabetes is associated with Th1 cytokines, a pattern similar to that seen in the NOD mouse. It has been shown in numerous studies of the NOD mouse that immune deviation to the Th2 type, brought about, for example, by direct administration of cytokines such as IL-4 or IL-10, is capable of preventing diabetes development $(35,36)$. It should be cautioned, however, that cytokine shifts observed during other effective murine diabetes prevention therapies may simply be a consequence of the therapy, and not the mechanism responsible for diabetes prevention (37). It is interesting to note that anaphylaxis induction is possible only with higher doses of B:9-23 (although B:13-23 injections require lower doses), and that repeated injections of the lower dose $(10 \mu \mathrm{g})$ do not result in anaphylaxis but protect from diabetes. With increasing reports of self-peptide anaphylaxis, this suggests that self-peptide vaccines should be used at the lowest possible therapeutic dose. A trial in humans by the company Neurocrine using an altered-peptide ligand of insulin peptide B:9-23 is underway. It is certainly hoped that this peptide in humans will not induce allergic reactions, but this will need to be carefully monitored given the present and prior findings of allergic reactions to self-peptides. We are struck by the ability of these peptides in the absence of Freund's adjuvant to induce anti-self-peptide antibodies when administered subcutaneously.

\section{Acknowledgments}

This work was supported by grants from the NIH (DK32083, DK-55969, P30 DK-57516), the Autoimmunity
Center of Excellence (U19 AI-46374), and the Diabetes Endocrine Research Center (P30 DK-57516), and by the Juvenile Diabetes Foundation, the Children's Diabetes Foundation, and a Veterans Administration Merit Award. N. Abiru was supported by an American Diabetes Association mentor-based fellowship, and $\mathrm{H}$. Moriyama was supported by a postdoctoral fellowship from the Juvenile Diabetes Research Foundation. E. Liu was supported by NIH training grant T32 AI-07365.

1. Peakman, M., et al. 2001. Characterization of preparations of GAD65, proinsulin, and the islet tyrosine phosphatase IA-2 for use in detection of autoreactive T-cells in type 1 diabetes: report of phase II of the Second International Immunology of Diabetes Society Workshop for Standardization of T-cell assays in type 1 diabetes. Diabetes. 50:1749-1754.

2. Tian, J., et al. 1998. Infectious Th1 and Th2 autoimmunity in diabetesprone mice. Immunol. Rev. 164:119-127.

3. Kaufman, D.L., et al. 1993. Spontaneous loss of T-cell tolerance to glutamic acid decarboxylase in murine insulin-dependent diabetes. Nature. 366:69-72.

4. Tisch, R, et al. 1993. Immune response to glutamic acid decarboxylase correlates with insulitis in non-obese diabetic mice. Nature. 366:72-75.

5. Kawasaki, E., Yu, L., Rewers, M.J., Hutton, J.C., and Eisenbarth, G.S. 1998. Definition of multiple ICA512/phogrin autoantibody epitopes and detection of intramolecular epitope spreading in relatives of patients with type 1 diabetes. Diabetes. 47:733-742.

6. Daniel, D., Gill, R.G., Schloot, N., and Wegmann, D. 1995. Epitope specificity, cytokine production profile and diabetogenic activity of insulin-specific T cell clones isolated from NOD mice. Eur. J. Immunol. 25:1056-1062.

7. Wegmann, D.R., Norbury-Glaser, M., and Daniel, D. 1994. Insulin-specific T cells are a predominant component of islet infiltrates in pre-diabetic NOD mice. Eur. J. Immunol. 24:1853-1857.

8. Simone, E., et al. 1997. T cell receptor restriction of diabetogenic autoimmune NOD T cells. Proc. Natl. Acad. Sci. USA. 94:2518-2521.

9. Abiru, N., et al. 2000. Dual overlapping peptides recognized by insulin peptide B:9-23 reactive $\mathrm{T}$ cell receptor AV13S3 $\mathrm{T}$ cell clones of the NOD mouse. J. Autoimmun. 14:231-237.

10. Wong, F.S., et al. 1999. Identification of an MHC class I-restricted autoantigen in type 1 diabetes by screening an organ-specific cDNA library. Nat. Med. 5:1026-1031.

11. Abiru, N., et al. 2001. Peptide and MHC specific breaking of humoral tolerance to native insulin with the B:9-23 peptide in diabetes prone and normal mice. Diabetes. 50:1274-1281.

12. Alleva, D.G., et al. 2001. A disease-associated cellular immune response in type 1 diabetics to an immunodominant epitope of insulin. J. Clin. Invest. 107:173-180.

13. Lee, K.H., Wucherpfennig, K.W., and Wiley, D.C. 2001. Structure of a human insulin peptide/HLA-DQ8 complex and susceptibility to type 1 diabetes. Nat. Immunol. 2:501-507.

14. Kappos, L., et al. 2000. Induction of a non-encephalitogenic type $2 \mathrm{~T}$ helper-cell autoimmune response in multiple sclerosis after administration of an altered peptide ligand in a placebo-controlled, randomized phase II trial. The Altered Peptide Ligand in Relapsing MS Study Group. Nat. Med. 6:1176-1182.

15. Pedotti, R., et al. 2001. An unexpected version of horror autotoxicus: anaphylactic shock to a self-peptide. Nat. Immunol. 2:216-222.

16. Lenzen, S., et al. 2001. The LEW.1AR1/Ztm-iddm rat: a new model of spontaneous insulin-dependent diabetes mellitus. Diabetologia. 44:1189-1196.

17. Janeway, C.A., Travers, P., Walport, M., and Capra, J.D. 1999. Immunobiology: the immune system in health and disease. Elsevier Science. London, United Kingdom. 461-488.

18. Arimura, A., and Harada, M. 1991. Differential effect of a PAF antagonist CV-3988 on active and passive anaphylactic shock in various mouse strains. Lipids. 26:1386-1390.

19. Ishii, S., et al. 1998. Impaired anaphylactic responses with intact sensitivity to endotoxin in mice lacking a platelet-activating factor receptor. J. Exp. Med. 187:1779-1788.

20. Kimura, S., Watanabe, A., Takeuchi, M., Nagata, M., and Harada, M. 1998. Suppressive effects of antihistaminic and/or anti-PAF agents on passive anaphylactic shock in mice sensitized with allogeneic monoclonal IgE and IgG1 antibodies and hyperimmune serum. Immunol. Invest. 27:379-393.

21. Miyajima, I., et al. 1997. Systemic anaphylaxis in the mouse can be mediated largely through IgG1 and Fc gammaRIII. Assessment of the cardiopulmonary changes, mast cell degranulation, and death associated with active or IgE- or IgG1-dependent passive anaphylaxis. J. Clin. Invest. 99:901-914.

22. Dombrowicz, D., et al. 1997. Absence of Fc epsilonRI alpha chain results 
in upregulation of Fc gammaRIII-dependent mast cell degranulation and anaphylaxis. Evidence of competition between Fc epsilonRI and Fc gammaRIII for limiting amounts of FcR beta and gamma chains. J. Clin. Invest. 99:915-925.

23. Ujike, A., et al. 1999. Modulation of immunoglobulin (Ig)E-mediated systemic anaphylaxis by low-affinity Fc receptors for IgG. J. Exp. Med. 189:1573-1579.

24. Takai, T., Ono, M., Hikida, M., Ohmori, H., and Ravetch, J.V. 1996. Augmented humoral and anaphylactic responses in Fc gamma RII-deficient mice. Nature. 379:346-349.

25. Choi, I.H., et al. 1998. Immunoglobulin E-dependent active fatal anaphylaxis in mast cell-deficient mice. J. Exp. Med. 188:1587-1592.

26. Metzger, H., et al. 1986. The receptor with high affinity for immunoglobulin E. Annu. Rev. Immunol. 4:419-470.

27. Dombrowicz, D., Flamand, V., Brigman, K.K., Koller, B.H., and Kinet, J.P. 1993. Abolition of anaphylaxis by targeted disruption of the high affinity immunoglobulin E receptor alpha chain gene. Cell. 75:969-976.

28. Kimura, S., Watanabe, A., Nagata, M., Niinomi, Y., and Harada, M. 1996. Heterogeneity of drug susceptibility of mouse active anaphylactic shock. Immunol. Invest. 25:425-434.

29. Anderson, A.C., et al. 2000. High frequency of autoreactive myelin proteolipid protein-specific $T$ cells in the periphery of naive mice: mechanisms of selection of the self-reactive repertoire. J. Exp. Med. 191:761-770.

30. Klein, L., Klugmann, M., Nave, K.A., Tuohy, V.K., and Kyewski, B. 2000.
Shaping of the autoreactive T-cell repertoire by a splice variant of self protein expressed in thymic epithelial cells. Nat. Med 6:56-61.

31. Pugliese, A., et al. 2001. Self-antigen-presenting cells expressing diabetesassociated autoantigens exist in both thymus and peripheral lymphoid organs. J. Clin. Invest. 107:555-564.

32. Pugliese, A., et al. 1997. The insulin gene is transcribed in the human thymus and transcription levels correlate with allelic variation at the INS VNTR-IDDM2 susceptibility locus for type I diabetes. Nat. Genet. 15:293-297.

33. Heath, V.L., Moore, N.C., Parnell, S.M., and Mason, D.W. 1998. Intrathymic expression of genes involved in organ specific autoimmune disease. J. Autoimmun. 11:309-318.

34. Rojas, M., Hulbert, C., and Thomas, J.W. 2001. Anergy and not clonal ignorance determines the fate of $\mathrm{B}$ cells that recognize a physiological autoantigen. J. Immunol. 166:3194-3200.

35. Goudy, K., et al. 2001. Adeno-associated virus vector-mediated IL-10 gene delivery prevents type 1 diabetes in NOD mice. Proc. Natl. Acad. Sci. USA. 98:13913-13918.

36. Ko, K.S., Lee, M., Koh, J.J., and Kim, S.W. 2001. Combined administration of plasmids encoding IL-4 and IL-10 prevents the development of autoimmune diabetes in nonobese diabetic mice. Mol. Ther. 4:313-316.

37. Serreze, D.V., et al. 2001. Th1 to Th2 cytokine shifts in nonobese diabetic mice: sometimes an outcome, rather than the cause, of diabetes resistance elicited by immunostimulation. J. Immunol. 166:1352-1359. 